\title{
Paravalvular aortic abscess - the role of echocardiography
}

\author{
Vlatka Rešković Lukšić*, Kristina Marić Bešić, Nikša Drinković Jr, Nikša Drinković, \\ Jadranka Šeparović Hanževački \\ University Hospital Center Zagreb, Zagreb, Croatia
}

Abscess formation is a severe complication of infective endocarditis, associated with high mortality. The aortic valve (AV) and its adjacent ring are more susceptible to this complication which is being detected with increasing frequency with the use of transoesophageal echocardiography (TEE). We present a case of AV endocarditis with paravalvular abscessus formation.

A 58-year old patient was referred to our hospital because of acute severe aortic regurgitation (AR) after treatment of $\mathrm{AV}$ endocarditis (S. viridans) two months ago. We performed TEE which revealed paravalvular aortic abscess with spontaneous drainage into LV cavity. Moreover, severe AR and normal left ventricular (LV) function were noticed. Left coronary artery stem (LM) was originating from abscess cavity, while the origin of the right coronary artery was normal. MSCT angiography was performed because there was very thin border between the left atrium and abscess cavity, but it did not confirm origin of LMA from abscess cavity. Considering high risk procedure, coronary angiography was performed and revealed normal coronary arteries. The patient was referred to cardiac surgery. At the operation, ruptured abscess was found with pseudoaneurysm of the aorta in the region of the left coronary cusp and compromised the origin of LMA, confirming TEE findings. During prolonged operation (sec. Bentall), patient became hemodynamically unstable, with impaired of LV function; LV assist device was introduced, but eventually patient died during operation.
Unfortunately, our patient did not survive this fatal complication of acute endocarditis. It occurs in up to $30 \%$ of cases of native valve endocarditis and survival rate is about $76 \%$ for $\mathrm{AV}$, but with worse outcome ( $57 \%$ mortality) in the presence of significant valve regurgitation. It still remains a challenging problem for the surgical treatment. Preoperative TEE is the most important diagnostic tool for early diagnosis and decision making. In our case, LM origin from the abscess cavity was diagnosed only with TEE, other methods (MSCT, coronary angiography) could not confirm that finding.

Conclusions: TEE is necessary in evaluation of endocarditis complications. In a case where paravalvular abscess is present, pseudoaneurysm of the aorta and coronary ostia compression has to be ruled out.

KEYWORDS: echocardiography, endocarditis, paravalvular abscess, aortic valve, transoesophageal echocardiography.

\section{Received: $20^{\text {th }}$ Mar 2013}

*Address for correspondence: Klinički bolnički centar Zagreb, Kišpatićeva 12 , HR-10000 Zagreb, Croatia.

Phone: +385-1-2388-888

E-mail: vlatka.reskovic@gmail.com

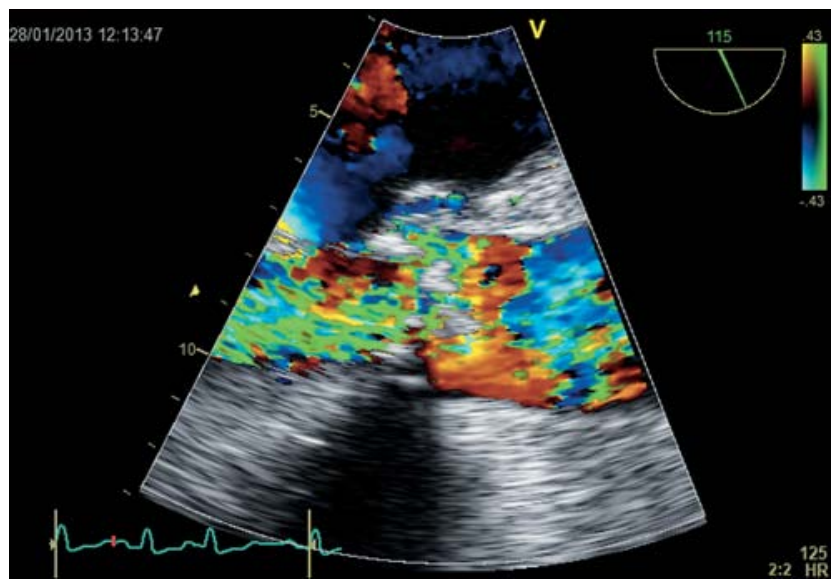

Figure 1. Severe aortc regurgitation jet.

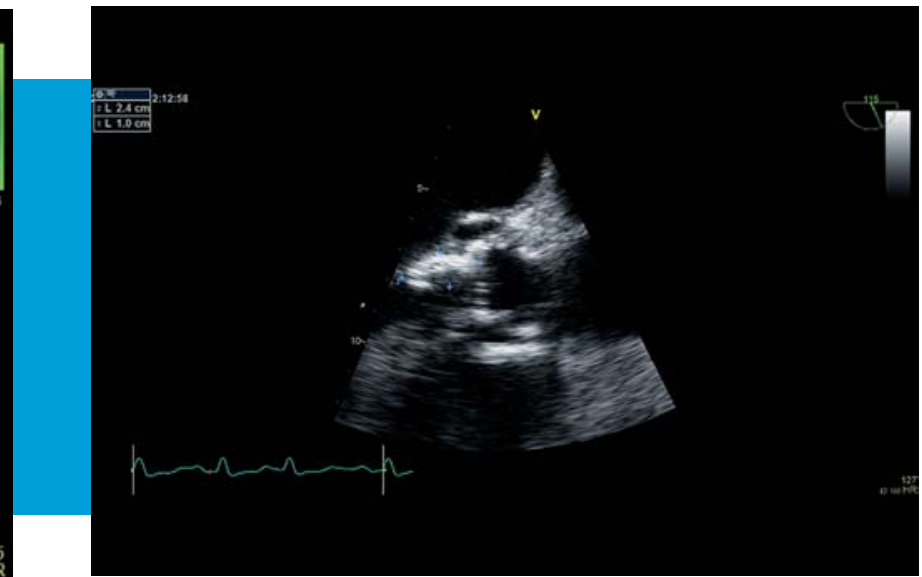

Figure 2. Aortic valve vegetations. 


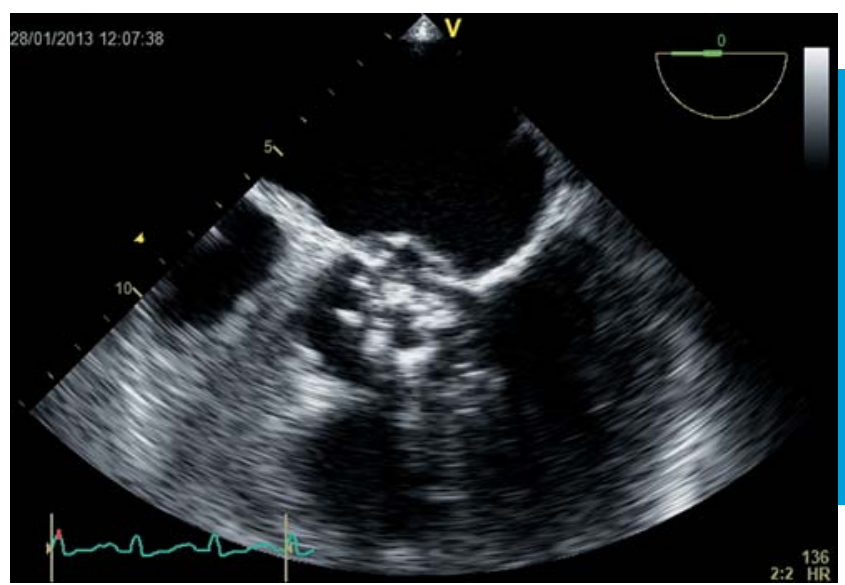

Figure 3. Abscess cavity with thin border to the left atrium.

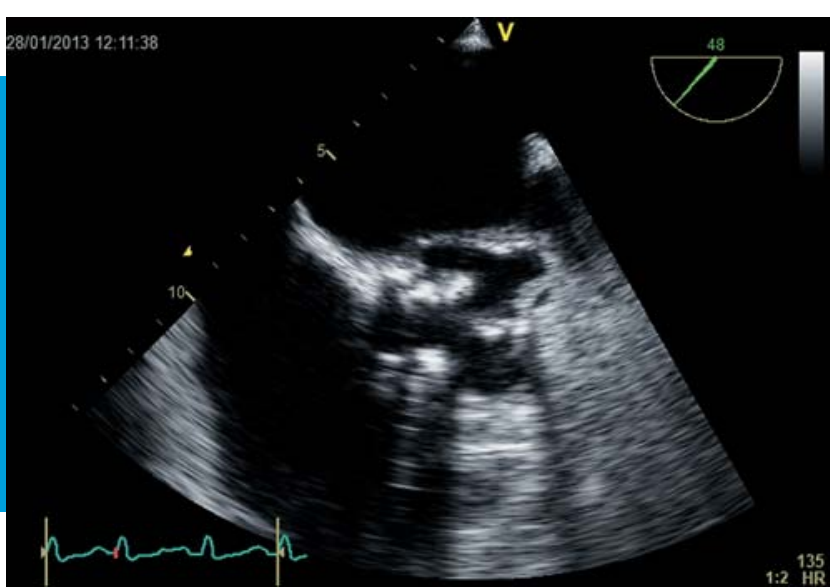

Figure 4. Origin of the left main coronary artery form abscess cavity.

\section{Literature}

1. Cosmi JE, Tunick PA, Kronzon I. Mortality in patients with paravalvular abscess diagnosed by transesophageal echocardiography. J Am Soc Echocardiogr. 2004;17(7):766-8. 2. Knosalla $\mathrm{C}$, Weng $\mathrm{Y}$, Yankah $\mathrm{AC}$, et al. Surgical treatment of active infective aortic valve endocarditis with associated periannular abscess - 11 year results. Eur Heart $\mathrm{J}$ 2000;21:490-7.

3. Okada K, Okita Y. Surgical treatment for aortic periannular abscess/pseudoaneurysm caused by infective endocarditis. Gen Thorac Cardiovasc Surg. 2013; 61(4):175-81.

4. David TE, Regesta T, Gavra G,Armstrong S, Maganti MD. Surgical treatment of paravalvular abscess: long-term results. Eur J Cardiothorac Surg. 2007;31(1):43-8. 